\title{
New Types of Employment, New Ways to Be Uncivil? A Thematic Analysis of Temporary Agency Workers' Exposure to Workplace Incivility
}

\author{
Kristoffer Holm, Eva Torkelson, Martin Bäckström \\ Department of Psychology, Lund University, Lund, Sweden \\ Email: Kristoffer.holm@psy.lu.se
}

Received 16 December 2015; accepted 17 January 2016; published 20 January 2016

Copyright (C) 2016 by authors and Scientific Research Publishing Inc.

This work is licensed under the Creative Commons Attribution International License (CC BY). http://creativecommons.org/licenses/by/4.0/

(c) $\underset{\mathrm{EY}}{\mathrm{O}}$ Open Access

\begin{abstract}
The aim of the study was to explore what types of incivility temporary agency workers might experience or witness. A total of 162 temporary agency workers ( 97 women and 65 men) from three unions and three temporary work agencies completed an online questionnaire. The questionnaire consisted of a one-item question, with an open-ended response format, regarding what types of incivility temporary agency workers might experience or witness in the workplace. The participants were employed in the sectors of healthcare, education, transportation, IT, retail and whitecollar service work. Overall, thematic analysis resulted in the identification of six themes: 1) exclusion from the collegiality, 2) with-holding information and resources, 3) acting condescendingly and using insulting remarks, 4) questioning competence and making higher demands, 5) threatening job security and using abusive terms of employment, and 6) showing more severe negative workplace behaviors. The results show that there are types of uncivil behaviors that are not fully captured by the most frequent used measures of today. Exclusion from the collegiality and not being respected for their competence, and condescending behavior were uncivil behaviors typically associated with temporary agency work. The study has implications for the future development of methods for studying incivility and negative workplace behaviors among temporary agency workers.
\end{abstract}

\section{Keywords}

Workplace Incivility, Temporary Agency Work, Contingent Work, Negative Workplace Behavior 


\section{Introduction}

In recent years interest in workplace incivility has increased in research concerning the broader field of negative interpersonal workplace behavior (Schilpzand, Pater, \& Erez, 2014). Changes in type of work, demands, temporary employment contracts and dissolution of traditional norms have been associated with workplace incivility (Pearson, Andersson, \& Porath, 2005). It is therefore particularly relevant to study incivility within contemporary working settings and the increasing population of contingent workers.

Workplace incivility is a mild form of negative workplace behavior that is characterized by its lower intensity and ambiguous intent to harm, differentiating it from more overt forms of workplace mistreatment such as bullying (Pearson, Andersson, \& Wegner, 2001). Although workplace incivility is a milder form of negative behavior it has negative consequences for the organization in the form of lower levels of well-being (Lim, Cortina, \& Magley, 2008; Holm, Torkelson, \& Bäckström, 2015; Reio \& Ghosh, 2009), lower commitment, lower job satisfaction, and higher turnover intentions among employees (Laschinger, Leiter, Day, \& Gilin, 2009).

More specifically, workplace incivility has been defined as “... low-intensity deviant behavior with ambiguous intent to harm the target, in violation of workplace norms for mutual respect. Uncivil behaviors are characteristically rude and discourteous, displaying a lack of regard for others” (Andersson \& Pearson, 1999: p. 457). Although there have been other definitions offered by, for instance, Zauderer (2002), the definition presented by Andersson and Pearson (1999) is the one most widely cited in research on workplace incivility (Hutton, 2006). Making demeaning remarks and ignoring colleagues are examples of uncivil behaviors (Pearson \& Porath, 2009).

Andersson and Pearson (1999) have suggested that workplace incivility can activate a social process in the organization, where uncivilized behavior creates spirals of increasing negative exchanges among co-workers. Both experiencing and witnessing workplace incivility has been related to instigating incivility (Ferguson \& Barry, 2011; Fevre, Lewis, Robinson, \& Jones, 2012; Gallus, Bunk, Matthews, Barnes-Farrell, \& Magley, 2014; Holm, Torkelson, \& Bäckström, 2015). This shows the potential of incivility to spread throughout the organization. As workplace incivility can permeate the organization, studying it from different perspectives, such as targets, witnesses and instigators, is important. In addition, workplace incivility has been shown to be exercised by both co-workers and supervisors in the workplace (Reio \& Sanders-Reio, 2011).

There have been a number of attempts to measure workplace incivility, but the Workplace Incivility Scale (WIS), developed by Cortina, Magley, Williams and Langhout (2001), has been the most frequent tool used to measure it. Although the WIS has satisfactory psychometrical properties (Martin \& Hine, 2005), incivility has been suggested to be a phenomenon that is difficult to detect and measure due to its subtle nature (Lim \& Lee, 2011). It has also been argued that the WIS does not comprehensively measure the full construct of workplace incivility, as it does not fully capture the intentionality and the intensity of behavior (Hershcovis, 2011). This constitutes a substantial problem in the literature as intentionality and intensity are key components of workplace incivility as defined by Andersson and Pearson (1999). These components distinguish incivility from other, more overt forms of negative workplace behavior. In addition, Tepper and Henle (2011) pointed out that workplace norms can vary across workplaces. Due to this, using standardized survey items could be problematic, as they are not necessarily generalizable over workplaces. Together, this suggests that the field is open to the development of new measures and refinements in relation to the concept of incivility.

Furthermore, other ways of approaching research on workplace incivility, such as qualitative study designs, to complement current work, have been requested by researchers (Robinson, Wang, \& Kiewits, 2014). One way of supplementing current literature on workplace incivility is to ask people to describe incidents they have observed or perpetrated. Consequently subjecting these reports to content analysis could act as a first means of subsequently developing survey items (Tepper \& Henle, 2011). This method could be a step towards untangling the conceptual confusion in workplace mistreatment constructs, and a way of discovering new types of negative workplace behaviors that have not previously been identified and studied.

\subsection{New Forms of Negative Workplace Behavior}

Contemporary working life has been subject to major changes with an increased amount of short-term contracts (Allvin, Aronsson, Hagström, Johansson, \& Lundberg, 2011). As Pearson et al. (2005) suggest, reports of workplace incivility may increase in the new type of work, with dissolution of traditional norms, altered psychological contacts and lack of long-term organizational investment, with consequent shifts in retention and 
loyalty. They further point out that contract labor, freelancing and job-hopping can create problems in internalizing organizational values or norms for employees. Considering these changes, the modern type of work could be an important environment to consider when studying workplace incivility.

Drawing from past research on negative workplace behavior, efforts have been made to explore and discover new types of deviant or bullying behaviors by using qualitative methods. Using this approach to workplace bullying, women have been found to focus on less overt types of bullying behavior, such as relational aggression, a more subtle type of hostility focused on slandering co-workers and exclusion of relationships (Crothers, Lipinski, \& Minutolo, 2009). In similar approaches using grounded theory to discover bullying behaviors, other kinds of negative workplace behaviors were found to be common, such as not being heard or listened to (Lewis \& Orford, 2005). Other types of behavior found in similar exploratory studies include devaluation and betrayal of coworkers, as well as slander and rejection (Strandmark \& Hallberg, 2007). In a study by Wright, Mohr and Sinclair (2014), lack of respect was the most prevalent negative behavior in the workplace. In a recent study investigating micro aggressions, a construct that resembles incivility due to its subtle nature, it was found that employees devalued lower-status colleagues. This included ignoring, excluding or interrupting those lower in the hierarchy (Young, Anderson, \& Stewart, 2015). This type of research has discovered new types of negative behaviors in the workplace, which were not fully captured by survey items of existing scales designed to measure negative workplace behavior. It shows that qualitative analyses can contribute additional information about incivility and similar constructs. Granted the contextual shift in contemporary working life with an increase of contingent workers, it is warranted to explore new forms of workplace incivility. A group of contingent workers of special interest concerning workplace incivility is temporary agency workers. This is a group recently recognized as exposed to disrespectful treatment (Vorell \& McCarmack, 2015).

\subsection{Temporary Employments and Workplace Incivility}

Temporary employments are on the rise in the new economy, accounting for an increasing part of the workforce (Cappelli \& Keller, 2013; Halbesleben \& Clark, 2010; Pirani \& Salvini, 2015). However, temporary workers are a heterogeneous group, where only roughly $30 \%$ claim that they choose this type of employment voluntarily (Bernhard-Oettel, Isaksson, \& Bellaagh, 2008). A sector that has emerged recently is companies offering temporary agency workers for hire (Zhang, Bartram, McNeil, \& Dowling, 2014). Slightly higher numbers of males are temporary agency workers, and younger people are overrepresented in this form of employment (Håkansson \& Isidorsson, 2012). Temporary agency workers contribute to organizational flexibility (Walter, 2012), and in Sweden the turnover rate of temporary agency workers is over $40 \%$ higher than among permanent employees. The lack of other employment options is one suggested reason why individuals accept an insecure employment type as a temporary agency worker (Andersson \& Wadensjö, 2004).

Although the use of contingent workers is becoming more common, limited research exists on negative implications for this group (Halbesleben \& Clark, 2010). Temporary work has been related to lower health, with an association between the time spent employed as a temporary worker and the deterioration of health (Pirani \& Salvini, 2015). Additionally, temporary workers report exhaustion (Mauno et al., 2015), less support and more isolation from others (Halbesleben \& Clark, 2010), as well as being marginalized, disrespectfully treated, or not acknowledged for their competence (Vorell \& McCarmack, 2015). Permanent employees might not be open to attempts to integrate in the group from temporary agency workers (Mitlacher, 2008).

To summarize, with the increasing number of employments of this type, and the difficulties in integrating temporary employees in the workplace, the group of temporary agency workers constitutes an interesting population to study from the perspective of workplace incivility. We expect that the temporary agency workers will reveal new types of workplace incivility.

\subsection{Aim of the Study}

The aim of the present study was to explore workplace incivility that temporary agency workers might experience or witness. By means of a survey concerning workplace incivility using an open-ended response format, the goal was to gain information about the different types of workplace incivility expressed by the participants. The study aims to add knowledge about new types of incivility in contemporary working life, and to contribute to the field by supplementing quantitative work carried out previously on workplace incivility. 


\section{Method}

\subsection{Participants}

One hundred and sixty-two temporary agency workers replied to a call for participation in a study concerning workplace incivility. The request was distributed by e-mail, which included a link to an internet survey, through three workers' unions and three temporary work agencies. Of the sample, 48 participants were employed in the healthcare sector (29.6\%), 39 in the educational sector (24.1\%), 31 in the transportation industry (19.1\%), 24 in IT (14.8\%), 12 in retail (7.4\%), and 8 were employed as white-collar knowledge workers (4.9\%). The mean age among participants was 43.6 years $(S D=13.5)$. Participants had been employed as temporary agency workers for a mean of 37.6 months $(S D=40.9)$.

\subsection{Materials}

The online survey consisted of demographic variables as well as an open-ended question to capture uncivilized behavior that the participants had either experienced or witnessed.

Demographic variables. Demographic questions concerned gender, age, and length of employment as a temporary agency worker (in months).

Workplace incivility. Information about uncivil behaviors in the workplace was gathered by the use of a question with an open-ended response format that asked what forms of workplace incivility temporary agency workers might be subjected to in the workplace. This question was "In what ways can you be disrespectfully/uncivilly treated as a temporary agency worker?” Participants were encouraged to give several examples of what they had experienced or witnessed.

\subsection{Procedure}

An e-mail which included a link to an online survey was administered by affiliate contacts in three Swedish workers union and three temporary work agencies and distributed to individuals employed as temporary agency workers. As time progressed, weekly reminders were sent out to the individuals who had received the survey. The survey took roughly 10 minutes to complete.

\subsection{Ethical Considerations}

In order to assure that participation in the study was fully anonymous, data were held securely for analysis, and not stored together with any identifiable information. In a cover letter that participants received, they were informed of the purpose of the study, as well as their possibility to withdraw at any time. The study was approved (reg. no. 2015/547) by the Regional Board of Ethical Review (EPN, www.epn.se/sv/lund) in Lund, Sweden.

\subsection{Strategy of Analysis}

Qualitative analysis was employed on material collected from the open-ended survey questions. The computer software program NVivo was used to categorize data and to conduct a thematic analysis (Parker, 2005). The responses were coded into themes and analyzed in several steps. Initially, the analyses were conducted individually by the authors to identify themes. Following this, discussions were held regarding the findings, and an integration of themes was made. The themes identified by each individual researcher were similar upon comparison. This was followed by further analysis of the content, refining the definitions of the themes and thereby producing the results of the study.

\section{Results}

Analyses of the responses from the participants resulted in six themes. These themes were exclusion from the collegiality, withholding information and resources, acting condescendingly and using insulting remarks, questioning competence and making higher demands, threatening job security and using abusive terms of employment, and showing more severe negative workplace behavior.

\subsection{Theme 1. Exclusion from the Collegiality}

A recurring theme was that temporary agency workers reported a hard time integrating and joining the collegial- 
ity of their workplaces. This is shown through not being seen in the workplace, not being considered a member of the staff, and feeling like a second-class employee at work or being considered an "outsider". One informant wrote:

"Large (degree of) alienation as we who are consultants are a part of the B-team."

Another informant experienced exclusion and wrote:

"Uncivilized conduct like no greetings from some. The same people ignore me and won't speak to me, but can speak a lot to the permanent employees."

Temporary workers say that they are not invited to join the regular staff for lunch, coffee breaks and parties that are held among the permanent staff:

"When I was a consultant (years ago) the others in the group that I worked in wouldn't eat lunch with me or socialize with me. They only talked to me regarding work."

Another informant commented:

"In many of the places I've worked at, the hired (temporary) employees are by themselves and never become one with the rest of the group, and the hired employees are often seen as tools that you can do as you wish with."

Furthermore being excluded, or not being included, is shown in more obvious ways, such as not being greeted properly or wearing different clothes.

"Many times when you greet others (that you do not know very well) in the hallway, it isn't certain that you will get a good morning or hello back."

"You're never accepted in the same way as the company's permanent employees because you're wearing other clothes."

As a temporary agency worker reported, there is a lack of social support in the workplace from coworkers and supervisors.

"If you're insecure about your work tasks and ask for help you don't get the same support as permanent personnel-you're expected to know this if you work for a higher hourly wage.”

Temporary agency worker reported that these aspects make them feel less supported as well as excluded from the workforce, and considered as second-grade employees, not seen as an equal individual at work or considered a part of the workplace.

\subsection{Theme 2. Withholding Information and Resources}

Another theme that emerged was the lack of information and resources reported by temporary agency workers. Temporary agency workers reported that this could be shown when arriving at a new workplace and not having a proper introduction to tasks or being met with expectations that they already should have full knowledge of all work tasks.

"Nobody knows that you're coming. Nobody to ask, no name of a person to turn to. [...] No work clothes, no access cards. No designated workspace, no instructions/information. Everyone was busy with their own thing and nobody wanted to help me.”

Additionally, temporary agency workers said that they are not part of the loop of information, making their work tasks more difficult to perform.

"As a consultant you never get an introduction, new employees, that I often have to take care of, get a whole different entry and of course a welcoming flower on the desk that I often order."

Resources can also be scarce for the temporary agency worker, as they perceive that they do not get the adequate tools to perform their job. One informant explains:

“... for instance not receiving the work tools that are reasonable to perform one's work, such as a key or a telephone”.

Others reported lack of equipment resulting in an un-ergonomic or hazardous work environment:

"We're outdoors with a cold-water compressor and (we are) washing parts of porcelain. Safety clothes? Why? If we get sick they hire new (people)."

\subsection{Theme 3. Acting Condescendingly and Using Insulting Remarks}

A third theme from the participants' reports of incivility consists of expressions of being submitted to condescending and demeaning remarks and behavior, with derogatory comments and expressions from superiors and colleagues, here exemplified by the report of one respondent: 
“When you ask for help you're met with rolling eyes or comments like ‘Can’t you do that yourself?’”

Additionally, gossiping and talking behind the backs of temporary agency workers occurred, as witnessed by one temporary agency worker.

"There's also talk behind your back, and no co-worker is there to defend you."

In a more obvious way, being yelled at or insulted showed how temporary agency workers experienced that they were mistreated in the workplace, exemplified by one informant from the healthcare sector:

"I ran there breathless, with a borrowed access card, and I am met by two chief physicians that completely chastise me; why am I late? Who the hell am I? And am I really qualified? I was completely put down.”

Sometimes jokes were made at the expense of the temporary agency worker, and the nature of his or her employment:

"This is a real crappy assignment, simply a temporary agency worker assignment! *Hahaha!*”

Various reports of condescending and demeaning behavior were provided by the respondents of the study, in both subtle and more overt ways, including body language, tone of voice, facial expressions and open comments.

\subsection{Theme 4. Questioning Competence and Making Higher Demands}

Another recurring theme in the reports of temporary agency workers was having their competence called into question, as well as experiencing higher demands than permanent employees. Several temporary agency workers reported that they were not trusted to be as competent as ordinary employees were, and were given work tasks that were considered less prestigious. Temporary agency worker reported that demands on them were higher than on permanent employees.

"(You are) Put under higher demands that everything should be ready when you leave a shift. No room is given to ask a co-worker to take over work tasks."

The temporary agency workers experienced that they always had higher expectations to deliver, never to miss a work opportunity and not to complain.

"We were constantly discriminated against in the workplaces we were hired by, as we were seen as a disposable workforce. We were forced to work until our bodies couldn't take it anymore and after that we were discarded and reorganized to new workplaces."

There was also a clear distinction in which the work tasks of a temporary agency worker were sometimes not appropriate to their competence or experience. One informant explains the difference with the following:

"You get to do the crappiest jobs, you get the heaviest patients."

Another informant phrased it:

"As a temporary agency worker you get to do the most unrewarding jobs, and permanent staff like the shift supervisor let you openly know that you get to do it just because you're a temporary agency worker."

Several temporary agency workers reported that their competence had been called into question when arriving to a new workplace, and that they were put down and placed on more menial tasks for being a temporary agency worker.

"Competence is called into question and the reason that you're working as a temporary agency worker is implied to be because of incompetence."

"A common conception among both supervisors in the workplace you're hired to, and the permanent staff, is that a temporary agency worker is less intelligent, less talented, and a worse worker than the permanent employees. These opinions are heard daily in the workplaces I've been working at.”

This put a feeling of higher demands on the temporary agency workers, and they perceived a constant need to prove themselves in terms of competence for their permanently employed peers and supervisors, in order to keep their employment.

\subsection{Theme 5. Threatening Job Security and Using Abusive Terms of Employment}

The unique position of the temporary agency workers was reflected in the terms of employment and job insecurity of participants in the study. Several participants report threats from their supervisor of being terminated from their current workplace, or actually being terminated from their current employment. In addition, temporary agency workers reported a fear of being critical, such as pointing out problems in the workplace, due to the risk of being terminated for being a problematic employee, not knowing whether they will be employed from one day to the next. 
“The shift supervisor yells at them (temporary agency workers) and they can't argue because then they are out. That's the reality for a lot of temporary agency workers, the bosses don't have to be uncivil, they just inform the temporary work agency that the person can't work there anymore.”

Some even reported having been threatened directly:

"If you were to point something out, you are reminded by your supervisor/boss in a 'nice' way that it is up to them if you have a job tomorrow or not."

"Another common violation was that if we pointed out flaws in, for instance, security or terms of employment we quickly got reorganized to a different workplace. It is therefore very difficult to organize collectively through a union as the employees were constantly being replaced.”

Furthermore, the temporary agency workers report being in a unique, third-party position, trapped between agency, union and employer:

"Between the lines temporary agency work is considered the problem and root of all evil, but it's not openly spoken about to colleagues. As you switch between different companies and therefore different collective agreements (union agreements), but in no way can you switch between unions several times a week, an illusion of disloyalty is spread in the local union clubs that temporary agency workers are freeriding.”

The experience was that normal employment terms do not apply, and that the unions are not capable of assisting the temporary agency workers in maintaining adequate terms of employment.

In addition to this, some temporary agency workers reported problems from their own agencies:

“A popular strategy for our own consultant directors was attempting to get employees to personally terminate their employments by constantly changing the schedule for those the employer considered annoying or problematic. A typical week could mean that you were working the night shift on Monday (22:30-05:30), daytime during Wednesday (07:00-16:00) and night again on Friday. A circadian rhythm to speak of was not the case during these periods and it was followed by a lot of tiredness and depression. I was also relocated between different workplaces by the consultant directors every week to enhance the feeling that you were replaceable and not to give us a sense of continuity."

This would leave the employee feeling disadvantaged from all ends: the employers, the agencies and the unions.

\subsection{Theme 6. Showing More Severe Negative Workplace Behavior}

A further theme of uncivil behavior reported by respondents was behavior considered as more severe negative workplace behavior than workplace incivility. This included the occurrence of bullying, harassment, threats of violence and even physical abuse. One respondent wrote:

"I have also been informed by a coworker that she has been physically attacked in the form of pushing."

Another respondent describes how threats occurred in the workplace:

"(I was) threatened by a doctor to be cut in pieces; a nurse who was going to hit me in the head with an iron pipe if I didn’t do as he said; threatened by a supervisor who didn't have evidence that I had been sleeping on the job, and if I didn't admit it, the punishment would be doubled.”

Being treated differently due to ethnicity and gender was additionally reported by some participants. This type of conduct is prohibited by law in Sweden, and thus considered a more severe type of negative workplace behavior.

In one particular case, a respondent reports being consistently harassed, accused of breaking the law, fired, and finally persecuted in public media, in a way that the respondent considers would damage his professional reputation. The text described the vulnerability of a temporary agency worker when being subjected to false accusations regarding his profession, spreading of rumors and being persecuted in media.

“This is what you are subjected to when you work as a temporary worker, as you aren't a part of the social network that a workplace in general has, and there is no protection or union to assist.”

The same six themes identified in the current study were found in almost every organization. The experiences of temporary agency workers were however similar, and the most prominent themes in the study were being excluded from the workforce, having information or resources withheld, and being subjected to condescending demeanor and insulting remarks.

\section{Discussion}

The aim of the present study was to explore what types of incivility temporary agency workers have experienced 
or witnessed. Thematic analysis of the data revealed six recurring themes of negative workplace behaviors that temporary agency workers experienced or witnessed. The themes were: exclusion from the collegiality, withholding information and resources, acting condescendingly and using insulting remarks, questioning competence and making higher demands, threatening job security and using abusive terms of employment, and showing more severe negative workplace behavior. These themes summarize what types of incivility temporary agency workers experience or witness at work.

The results are interesting in relation to the Workplace Incivility Scale (WIS) constructed by Cortina et al. (2001). The scale contains seven items: 1) put you down or was condescending to you, 2) paid little attention to your statement or showed little interest in your opinion, 3) made demeaning or derogatory remarks about you, 4) addressed you in unprofessional terms, either publicly or privately, 5) ignored or excluded you from the professional camaraderie, 6) doubted your judgement on matters over which you have responsibility, and 7) made unwanted attempts to draw you into a discussion of personal matters. Some of the themes found in the present study, for instance exclusion from the collegiality, acting condescendingly and using insulting remarks and questioning competence and making higher demands, correspond very well to the following items from the scale: 1) put you down or was condescending to you, 3) made demeaning or derogatory remarks about you, 5) ignored or excluded from the professional camaraderie and 6) doubted your judgement on matters of which you have responsibility. One of the most prominent themes, exclusion from the collegiality, occurs in the scale, showing the versatility of the WIS. However, the themes withholding information or resources, threatening job security and using abusive terms of employment, and showing more severe negative workplace behavior differed to some extent from the items found in the WIS. This suggests that the scale manages to capture many of the experiences of workplace incivility in the present study, but that there is room for additional scale expansion and development to measure more comprehensively experiences of incivility in the group of temporary agency workers.

Hershcovis (2011) has previously disputed the scale, and it is possible that the scale could benefit from being further developed by including items based on some of the themes found in the present work. In particular, measures of incivility could be adapted when investigating specific groups, such as temporary agency workers. Different types of employments carry different work environments, which should be considered in future studies of workplace incivility on various subgroups. This is particularly evident with the theme of threatening job security and using abusive terms of employment, which is very specific to the employment situation of a temporary agency worker ${ }^{1}$. The present study is a study of the perceived exposure to incivility for temporary agency workers, where the findings of the present work show that there are types of incivility that are not encompassed in today's measures. This suggest that there may be uncivil behaviors that are not included in research on incivility. The present study can be used as an inspiration when new instruments are developed or when incivility is investigated with other measures, e.g. interviews, in similar contexts.

The results of the study, particularly concerning exclusion from the collegiality, as well as questioning competence and making higher demands, are in line with previous research which states that temporary workers report isolation and low support (Halbesleben \& Clark, 2010), have a hard time becoming integrated in the workgroup (Mitlacher, 2008), and are marginalized and not respected for their competence (Vorell \& McCarmack, 2015). Furthermore, that uncivil behavior was sometimes disguised as jokes is in line with research on workplace bullying, which found jokes to be a disguise for improper behavior in the workplace (Collinson, 1988). As Young, Anderson and Stewart (2015) pointed out in their study of micro aggressions, excluding or interrupting those lower in the hierarchy was common. These behaviors were also found in the present study, possibly due to temporary agency workers having lower social status than permanent employees. Cortina (2008) discussed the possibility of certain groups being particularly at risk of experiencing uncivil behaviors in the workplace, such as women, ethnic minorities, in the form of selective incivility as a type of discrimination. Temporary agency workers could be at higher risk of experiencing behaviors such as exclusion, not being respected for their competence or condescending behavior, as this group might have a harder time integrating in the workgroup, or becoming fully respected as a part of the team, thus having lower status in the workplace.

It is worth noting that some types of uncivilized behaviors appear to be tightly linked to the form of employment for temporary agency workers. Having less job security and experiencing exclusion from the collegiality

\footnotetext{
${ }^{1}$ It should be noted that labor regulation in Sweden grants permanent employees a comprehensive amount of job security. Temporary agency workers do not have as firm regulation of employment contracts, and thus less innate job security follows with the employment form. Beyond a Swedish context, this could be relevant for other countries with similar types of labor regulations.
} 
due to being an external consultant are aspects directly linked to the role of a temporary agency worker. It falls naturally in the role of the temporary agency worker not to have the same benefits as permanent employees, and not to have the same social relationships. The temporary agency worker is often a new addition to the workplace, which makes it more difficult for them to integrate and acquire the same benefits. This shows that the group consequently could be at specific risk of experiencing these forms of incivility more explicitly, merely based on their employment type. Future studies should examine more deeply the work situation for temporary agency workers, and explore whether they are at risk of being extra exposed to negative workplace behaviors. For instance, a practical next step could be measuring the frequency of workplace incivility in the group of temporary agency workers, in comparison to permanent employees.

\subsection{Limitations}

Some limitations of the present study should be mentioned. It is possible that the themes discovered in the present work are too broad to capture lesser distinctions in incivility among temporary agency workers. It is also possible that there are other ways of categorizing the results. Additionally, it is conceivable that there are other types of incivility that temporary agency workers experience which did not emerge in this study. However, it has been noted in the past that in qualitative research, twenty informants are often considered sufficient to capture variations in the experience of a phenomenon (Sandberg, 2000), whereas the present study contained 162 respondents. On the other hand, many qualitative studies consist of lengthy interviews, and this study only included one single question. The high number of respondents and the variability in worker settings may have compensated for the rather meager amount of information from each participant.

Furthermore, the themes could to some extent overlap, as withholding resources and excluding an individual carry similar properties. In the same way, having job security threatened could be considered condescending by an individual, depending on the tone of voice, body language and so forth. Another limitation concerns the use of language and semantics. As a qualitative analysis concerns the meaning of words in a given context, it is always susceptible to the vulnerability of individuals interpreting words differently. Despite offering a brief stipulation in the questionnaire of what disrespectful/uncivil behaviors pertain to, it is possible that some participants of the study had a different interpretation of this phenomenon, which would affect their responses to the questionnaire. Lastly, the study was conducted in Sweden. There is a possibility that this could have affected the findings of the study, and that it can differ in other countries. An example of this is the quite specific nature of Swedish labor regulations and job security differences between permanent workers and temporary agency workers.

\subsection{Conclusion}

To conclude, temporary agency workers have experienced or witnessed uncivil behaviors in the form of exclusion from the collegiality, withholding information and resources, acting condescendingly and using insulting remarks, questioning competence and making higher demands, threatening job security and using abusive terms of employment, and showing more severe negative workplace behavior. The results show that there are uncivil behaviors not fully captured by the most frequent used instruments of today. It also shows that some uncivilized behaviors can be linked to temporary agency workers, such as exclusion from the collegiality and not being respected for their competence or condescending behavior. This indicates that new types of employment carry new types of incivility. The study could be used as a basis for developing measurements of workplace incivility, and advancing research on the importance of employment type in relation to negative workplace behaviors.

\section{Acknowledgements}

The project is financed by the FORTE (The Swedish Research Council for Health, Working Life and Welfare (DNR 2012-0138).

\section{References}

Andersson, L. M., \& Pearson, C. M. (1999). Tit for Tat? The Spiraling Effect of Incivility in the Workplace. Academy of Management Review, 24, 452-471.

Allvin, M., Aronsson, G., Hagström, T., Johansson, G., \& Lundberg, U. (2011). Work without Boundaries: Psychological 
Perspectives on the New Working Life. Chichester: Wiley Blackwell. http://dx.doi.org/10.1002/9781119991236

Andersson, P., \& Wadensjö, E. (2004). Hur fungerar bemanningsbranchen? Literature Review Report 2004: 15 Institutet för Arbetsmarknadspolitisk Utvärdering.

Bernhard-Oettel, C., Isaksson, K., \& Bellaagh, K. (2008). Patterns of Contract Motives and Work Involvement in Temporary Work: Relationships to Work-Related and General Well-being. Economic and Industrial Democracy, 29, 565-591. http://dx.doi.org/10.1177/0143831X08096231

Cappelli, P., \& Keller, J. R. (2013). Classifying Work in the New Economy. Academy of Management Review, 38, 575-596. http://dx.doi.org/10.5465/amr.2011.0302

Collinson, D. L. (1988). “Engineering Humour”: Masculinity, Joking and Conflict in Shop-Floor Relations. Organization Studies, 9, 181-199. http://dx.doi.org/10.1177/017084068800900203

Cortina, L. M. (2008). Unseen Injustice: Incivility as a Modern Form of Discrimination in Organizations. Academy of Management Review, 33, 55-75. http://dx.doi.org/10.5465/AMR.2008.27745097

Cortina, L. M., Magley, V. J., Williams, J. H., \& Langhout, R. D. (2001). Incivility at the Workplace: Incidence and Impact. Journal of Occupational Health Psychology, 6, 64-80. http://dx.doi.org/10.1037/1076-8998.6.1.64

Crothers, L. M., Lipinski, J., \& Minutolo, M. C. (2009). Cliques, Rumors, and Gossip by the Water Cooler: Female Bullying in the Workplace. The Psychologist-Manager Journal, 12, 97-110. http://dx.doi.org/10.1080/10887150902886423

Ferguson, M., \& Barry, B. (2011). I Know What You Did: The Effects of Interpersonal Deviance on Bystanders. Journal of Occupational Health Psychology, 16, 80-94. http://dx.doi.org/10.1037/a0021708

Fevre, R., Lewis, D., Robinson, A., \& Jones, T. (2012). Trouble at Work. London: Bloomsbury.

Gallus, J. A., Bunk, J. A., Matthews, R. A., Barnes-Farrell, J. L., \& Magley, V. J. (2014). An Eye for an Eye? Exploring the Relationship between Workplace Incivility Experiences and Perpetration. Journal of Occupational Health Psychology, 19, 143-154. http://dx.doi.org/10.1037/a0035931

Håkansson, K., \& Isidorsson, T. (2012). Work Organizational Outcomes of the Use of Temporary Agency Workers. Organization Studies, 33, 487-505. http://dx.doi.org/10.1177/0170840612443456

Halbesleben, J. R. B., \& Clark, S. K. (2010). The Experience of Alienation among Temporary Workers in High-Skill Jobs: A Qualitative Analysis of Temporary Firefighters. Journal of Managerial Issues, 22, 531-545.

Hershcovis, M. S. (2011). “Incivility, Social Undermining, Bullying... Oh My!”: A Call to Reconcile Constructs within Workplace Aggression Research. Journal of Organizational Behavior, 32, 499-519. http://dx.doi.org/10.1002/job.689

Holm, K., Torkelson, E., \& Bäckström, M. (2015). Models of Workplace Incivility: The Relationships to Instigated Incivility and Negative Outcomes. BioMed Research International, 2015, Article ID: 920239. http://dx.doi.org/10.1155/2015/920239

Hutton, S. A. (2006). Workplace Incivility: State of the Science. The Journal of Nursing Administration, 36, 22-28. http://dx.doi.org/10.1097/00005110-200601000-00006

Laschinger, H. K. S., Leiter, M., Day, A., \& Gilin, D. (2009). Workplace Empowerment, Incivility, and Burnout: Impact on Staff Nurse Recruitment and Retention Outcomes. Journal of Nursing Management, 17, 302-311. http://dx.doi.org/10.1111/j.1365-2834.2009.00999.x

Lewis, S. E., \& Orford, J. (2005). Women’s Experiences of Workplace Bullying: Changes in Social Relationships. Journal of Community \& Applied Social Psychology, 15, 29-47. http://dx.doi.org/10.1002/casp.807

Lim, S., Cortina, L. M., \& Magley, V. J. (2008). Personal and Workgroup Incivility: Impact on Work and Health Outcomes. Journal of Applied Psychology, 93, 95-107. http://dx.doi.org/10.1037/0021-9010.93.1.95

Lim, S., \& Lee, A. (2011). Work and Non-Work Outcomes of Workplace Incivility: Does Family Support Help? Journal of Occupational Health Psychology, 16, 95-111. http://dx.doi.org/10.1037/a0021726

Martin, R. J., \& Hine, D. W. (2005). Development and Validation of the Uncivil Workplace Behaviour Questionnaire. Journal of Occupational Health Psychology, 10, 477-490. http://dx.doi.org/10.1037/1076-8998.10.4.477

Mauno, S., De Cuyper, N., Kinnunen, U., Ruokolainen, M., Rantanen, J., \& Mäkikangas, A. (2015). The Prospective Effects of Work-Family Conflict and Enrichment on Job Exhaustion and Turnover Intentions: Comparing Long-Term Temporary vs. Permanent Workers across Three Waves. Work \& Stress, 29, 75-94.

Zhang, M. M. Q., Bartram, T., McNeil, N., \& Dowling, P. J. (2014). Towards a Research Agenda on the Sustainable and Socially Responsible Management of Agency Workers through a Flexicurity Model of HRM. Journal of Business Ethics, 127, 513-523. http://dx.doi.org/10.1007/s10551-013-2045-z

Mitlacher, L. W. (2008). Job Quality and Temporary Agency Work: Challenges for Human Resource Management in Triangular Employment Relations in Germany. The International Journal of Human Resource Management, 19, 446-460. http://dx.doi.org/10.1080/09585190801895528 
Parker, I. (2005). Qualitative Psychology: Introducing Radical Research. Maidenhead: Open University Press.

Pearson, C. M., Andersson, L. M., \& Porath, C. L. (2005). Workplace Incivility. In S. Fox, \& P. Spector (Eds.), Counterproductive Work Behaviour: Investigations of Actors and Targets (pp. 177-200). Washington DC: American Psychological Association. http://dx.doi.org/10.1037/10893-008

Pearson. C. M., Andersson. L. M., \& Wegner, M. J. (2001). When Workers Flout Convention: A Study of Workplace Incivility. Human Relations, 54, 1387-1419.

Pearson, C., \& Porath, C. (2009). The Costs of Bad Behavior: How Incivility Is Damaging Your Business and What to Do about It. New York: Penguin Books Ltd.

Pirani, E., \& Salvini, S. (2015). Is Temporary Employment Damaging to Health? A Longitudinal Study on Italian Workers. Social Science \& Medicine, 124, 121-131. http://dx.doi.org/10.1016/j.socscimed.2014.11.033

Reio, T., G., \& Ghosh, R. (2009). Antecedents and Outcomes of Workplace Incivility: Implications for Human Resource Development Research and Practice. Human Resource Development Quarterly, 20, 237-264. http://dx.doi.org/10.1002/hrdq.20020

Reio Jr., T. G., \& Sanders-Reio, J. (2011). Thinking about Workplace Engagement: Does Supervisor and Coworker Incivility Really Matter? Advances in Developing Human Resources, 13, 462-478. http://dx.doi.org/10.1177/1523422311430784

Robinson, S. L., Wang, W., \& Kiewitz, C. (2014). Coworkers Behaving Badly: The Impact of Coworker Deviant Behavior upon Individual Employees. Annual Review of Organizational Psychology and Organizational Behavior, 1, $123-143$.

Sandberg, J. (2000). Understanding Human Competence at Work: An Interpretive Approach. Academy of Management Journal, 43, 9-25. http://dx.doi.org/10.2307/1556383

Schilpzand, P., De Pater, I. E., \& Erez, A. (2014). Workplace Incivility: A Review of the Literature and Agenda for Future Research. Journal of Organizational Behavior, Published Online. http://dx.doi.org/10.1002/job.1976

Strandmark, M., \& Hallberg, L. R. M. (2007). Being Rejected and Expelled from the Workplace: Experiences of Bullying in the Public Service Sector. Qualitative Research in Psychology, 4, 1-14. http://dx.doi.org/10.1080/14780880701473359

Tepper, B. J., \& Henle, C. A. (2011). A Case for Recognizing Distinctions among Constructs That Capture Interpersonal Mistreatment in Work Organizations. Journal of Organizational Behavior, 32, 487-498. http://dx.doi.org/10.1002/job.688

Vorell, M. S., \& Carmack, H. J. (2015). Healing the Healer: Stress and Coping Strategies in the Field of Temporary Medical Work. Health Communication, 30, 398-408. http://dx.doi.org/10.1080/10410236.2013.865506

Walter, L. (2012). Matchningsfabriken. Arbetsmarknadoch Arbetsliv, 18, 35-50.

Wright, R. R., Mohr, C. D., \& Sinclair, R. R. (2014). Conflict on the Treatment Floor: An Investigation of Interpersonal Conflict Experienced by Nurses. Journal of Research in Nursing, 19, 26-37. http://dx.doi.org/10.1177/1744987113485577

Young, K., Anderson, M., \& Stewart, S. (2015). Hierarchical Microaggressions in Higher Education. Journal of Diversity in Higher Education, 8, 61-71. http://dx.doi.org/10.1037/a0038464

Zauderer, G. (2002). Workplace Incivility and the Management of Human Capital. Public Manager, 31, 36-43. 